\title{
PRINCIPLES OF TEXTBOOK ANALYSIS
}

\author{
A Review of J. R. Millenson's Principles of Behavioral Analysis. ${ }^{1}$
}

\author{
T. Verhave ${ }^{2}$ and J. Gilmour Sherman
}

ARIZONA STATE UNIVERSITY

In evaluating any new book of a scholarly or technical nature, one has to consider the purpose for which it was written, for it is all too easy to attack it for not being something else. While other categories are possible, it seems that a book in psychology can be thought of as serving one or more of five functions:

(1) It can provide new information (for exple, Hull's Hypnosis and Suggestibility [1933] or Skinner's The Behavior of $\mathrm{Or}$ ganisms [1938]).

(2) It can attempt an extensive or definitive summary and digest of an available body of knowledge (for example, Cofer and Appley's Motivation: Theory and Research [1964] or Munn's Handbook of Psychological Research on the Rat [1950]).

(3) It can provide a new organization of existing information (for example, Keller and Schoenfeld's Principles of Psychology [1950] or Galanter's Textbook of Elementary Psychology [1961]).

(4) It can present conventional material in a new mode, as did the programmed text by Holland and Skinner (1961).

(5) Finally, there are the subsidiary books, such as collections of readings, laboratory manuals, and brief primers, all of which are primarily intended to be used in conjunction with a more substantial text.

The criteria of success are different in each case, and a book intended to fulfill one function should not be faulted for failing to meet the criteria of another.

\footnotetext{
${ }^{1}$ New York: Macmillan, 1967. Pp. xxii $+488, \$ 7.95$.

${ }^{2}$ Reprints may be obtained from Thom Verhave, Department of Psychology, Queens College of the City University of New York, Flushing, New York 11367.
}

Most textbooks in psychology, and particularly the eclectic survey, are probably best placed in the second category because they do not provide any new organization of a coherent body of information. Some introductory texts, however, take a systematic approach, and belong to the third category. Such is J. R. Millenson's Principles of Behavioral Analysis, which provides an updated version of a previously successful systematic treatment (Keller and Schoenfeld, 1950).

The principal task for an introductory course in any science must be as clear and dedicated a presentation of fundamental concepts and theories as an author can muster. Even if a field is still relatively immature and undeveloped, a firm knowledge of fundamentals must be the basis for whatever is to be accomplished, either in subsequent courses, or by later generations. It is neither surprising nor alarming that, in a more or less unexplored domain, there should be different points of view, vocabularies, and schools of thought. No doubt, the relative maturity of a science is indicated by the extent to which such heterogeneity of treatment exists.

However, by not presenting an encyclopedic account, whether superficial or detailed, but by concentrating instead on the power, meaning, and scope of a limited number of basic concepts and ideas, one may hope to give the reader a view of psychology as an interconnected, even rational, subject matter. The particular set of concepts and topics selected by an author will always be open to argument and controversy. Which ones are selected, however, is a matter of less importance than the honest attempt to present them in a coherent and systematic framework, whether this be Titchenerian, Tolmanian, behavioristic, mentalistic, phenomenological, or whatever.

Nor are systematic books written in a manner which talks down to their audience. They 
are likely to be more difficult to read and teach from. They are the kind of book that Alfred North Whitehead (1929) evidently had in mind when he observed:

\begin{abstract}
"Whenever a textbook is written of real educational worth, you may be quite certain that some reviewer will say that it will be difficult to teach from it. Of course it will be difficult to teach from it. If it were easy, the book ought to be burned; for it cannot be educational. In education, as elsewhere, the broad primose path leads to a nasty place. This evil path is represented by a book or a set of lectures which will practically enable the student to learn by heart all the questions likely to be asked at the next examination."
\end{abstract}

The sentiment expressed here is not outdated, as indicated by Galanter's preface to his recent introductory text (1966). (Lest some readers either gleefully or scornfully take this to be an indictment of programmed instruction, let us assert that we think it has its place and uses: to help along the novice in a field.)

Ideally, a textbook is not just a consensus of a community of informed scholars or scientists. It also represents innovation and gives a challenging new idea or trend a prospect of more general acceptance. Psychology has known such texts, some more successful than others: Maurice Parmelee's The Science of Human Behavior (1913); Karl Muenzinger's Psychology: The Science of Behavior (1942); and F. S. Keller and W. N. Schoenfeld's Principles of Psychology (1950). G. A. Miller's Psychology: The Science of Mental Life (1962) and E. Galanter's Textbook of Elementary Psychology (1966) are of more recent vintage and use a mentalistic, rather than behavioristic, vocabulary.

What then is it that a systematic introductory text may set out to accomplish? We can do no better than to paraphrase Keller and Schoenfeld. The purpose of an introductory text in psychology, they wrote (p. 1), is threefold: (1) to acquaint the reader with a number of well-established basic principles; (2) to show how such principles are interrelated; and, (3) to suggest their relevance in the analysis and understanding of everyday human activity. In addition, one can adopt an historical approach to each of the various topics or concepts in turn, showing where they came from and how they evolved. This aspect was not emphasized in the Keller and Schoenfeld text, but it stood out clearly in Fred Keller's lectures.

With these preliminaries out of the way, let us turn to Millenson's Principles of Behavioral Analysis. As Millenson states in the Preface: “. . . the text attempts an unusual degree of systematization for the introductory level .... With a limited set of general concepts I have tried to build a sound framework so that the student, whether this be his first, only, or last course in the science, will be provided the means to interpret and order a wide variety of psychological phenomena" (p. xi). Since "the treatment of the field is in terms of functional behavior analysis, a point of view long associated with B. F. Skinner," the book places itself squarely in position as a successor to Keller and Schoenfeld's.

In what follows, we will, therefore, examine three main questions: (1) Does the book make an original contribution as a systematic treatise, even at the introductory level? (2) If not original as such, does it make a contribution as an updated version of Keller and Schoenfeld's text? (3) Is the book successful as a text? Unlike theoretical articles in journals, which also attempt a new organization of existing information, any introductory text, of necessity, must also meet the standards of a successful teaching instrument. However brilliant a book may appear to one's already knowledgeable colleagues, it cannot be acclaimed as a text if it does not teach. These, then, are the general guidelines used in our evaluation. Since our evaluation is negative on all three of these points, we will document our assertions in some detail. First, we examine the book as a systematic treatise by analyzing its organization, and by making selected comments on individual chapters; then we consider the book's status as a text.

Our reaction to the over-all organizational structure may be summarized by the following statements:

(1) To a large extent the book consists of an adaptation of the framework employed by Keller and Schoenfeld (1950). Deviations from that framework are often minor and, not infrequently, less than successful.

(2) Although the book presents new sub- 
stantive material not discussed in the Keller and Schoenfeld text, the new material is less successfully integrated within its theoretical framework.

(3) The above factors have produced a frequently illogical order of discussion of topics and/or concepts.

Here are our reasons for these conclusions. The book is divided into five main parts and 18 separate chapters (see Table 1 for summary contents). Each chapter is divided further into numbered sub-sections.

Table I

Organizational Structure of Book

(See Table of Contents)

\begin{tabular}{|c|c|}
\hline $\begin{array}{l}\text { Chapter } \\
\text { Number }\end{array}$ & Chapter Title \\
\hline \multicolumn{2}{|r|}{ Part I: The Lawfulness of Behavior } \\
\hline 1 & $\begin{array}{l}\text { A Background to the Scientific Approach to } \\
\text { Behavior }\end{array}$ \\
\hline 2 & Reflex (Elicited) Behavior \\
\hline 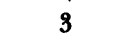 & Pavlovian Conditioning \\
\hline 4 & Operant Strengthening \\
\hline 5 & Operant Extinction and Reconditioning \\
\hline \multicolumn{2}{|r|}{ PART II: The Fundamental Units of Analysis } \\
\hline 6 & $\begin{array}{l}\text { Response and Stimulus Contingency Nota- } \\
\text { tion }\end{array}$ \\
\hline 7 & Intermittent Reinforcement \\
\hline 8 & Response Specification \\
\hline 9 & Environmental Control \\
\hline \multicolumn{2}{|r|}{ PART III: Compounding Behavioral Units } \\
\hline 10 & Discrimination \\
\hline 11 & Acquired Reinforcers \\
\hline 12 & Chaining \\
\hline \multicolumn{2}{|r|}{ PART IV: Complex Contingencies } \\
\hline 13 & Concept Acquisition \\
\hline 14 & Problem Solving and Intelligence \\
\hline \multicolumn{2}{|r|}{ PART V: Reinforcement Dynamics } \\
\hline 15 & Motivation I \\
\hline 16 & Motivation II \\
\hline 17 & Aversive Contingencies \\
\hline 18 & Emotional Behavior \\
\hline
\end{tabular}

Part I, "The Lawfulness of Behavior," consists of five chapters, Chapter 1 of which is historical in nature. We feel that this chapter does not belong in Part I, given the content and nature of its other chapters. The history of psychology seems a rather poor example of the lawfulness of behavior. It would have been better to allot a separate section to introduc- tory material, a practice followed in many other books (see, e.g., Skinner, 1953).

Before examining the content of this chapter in some detail, we must express our strong disagreement with the not infrequent practice of beginning an introductory text with a brief historical survey chapter. It is far from clear how it might be possible to present the history of a more or less technical or specialized subject matter in such a fashion as to be meaningful to an audience that presumably knows nothing about it as yet. What can be the value of mentioning to a freshman or sophomore the names of a few personal heroes whose feats, real or imagined, must of necessity remain obscure until he had advanced at least halfway through the rest of the book?

There are alternatives. We believe, as strongly as Millenson, that "there is no better way to understand the present activities of a science than through an acquaintance with its past" (p. 3). It is not really possible, however, to take Millenson's initial emphasis on the importance of "an acquaintance with (the) past" very seriously. The remainder of the book is almost completely a-historical. The background of his basic concepts and principles is nowhere to be found.

It would seem that there are two ways in which some historical sophistication can be imparted to the beginning student. One can weave historical material in throughout the entire fabric of the text, as done very successfully by George Miller (1962) in psychology and Taylor (1941) in physics, to mention two outstanding examples of this method. One can also present matters of historical interest in a separate section at the end of each chapter. This practice is less demanding, but can also be quite useful (see Kantor, 1924; Keller and Schoenfeld, 1950).

What about the content of Chapter 1 as a history of psychology or "behavioristics"? We can perhaps not be too critical of our author here. One of us, after some exposure to the current literature in the history of psychology, has come away rather unimpressed with the status of knowledge and scholarship in this field (Verhave, 1967). When presumed experts are frequently unfamiliar with the primary sources, those who rely on them become their ignorant victims.

It is, therefore, unfortunate that Millenson's knowledge of Aristotle's psychology is 
based on such a source as Toulin and Goodfield's The Architecture of Matter (1962) rather than Shute (1941), Randall (1960), Esper (1964), or Kantor (1963), not to mention Aristotle himself (e.g., McKeon, 1941).

A brief perusal of Watson (1963), Kantor (1963), or Brett (1962) might have helped to correct the erroneous view that the Medieval Church Fathers are to be blamed for inventing the "supernatural soul" (p. 4). The popular fiction that the Middle Ages contained nothing but unintelligible mumbo-jumbo dies hard indeed (Denake, 1966), but a look at Crombie's Medieval and Early Modern Science (1959) or Clagett'sThe Science of Mechanics in the Middle Ages (1959) might raise some doubts.

It is also a popular fiction among those who have read Skinner (1931) on the concept of the reflex that Descartes's description of the principle of the reflex "represents a partial break from the metaphysical explanations of behavior" (p. 4). First, analogies between mechanical or "automatic" toys, such as simple marionettes, date back at least as far as Aristotle (De Motu Animalium, 7, 701b; see also Esper, 1964, p. 171) and can be found throughout the entire literature of antiquity, the Middle Ages, and the Renaissance. Second, if one were familiar with the extent to which psychologists in the introspective (phenomenological) tradition currently pay homage to Descartes for his formulation of the "modern" version of the mind-body dichotomy, as well as his empasis on the soul ("I think, therefore I am"), one's enthusiasm would indeed be dimmed. In fact, as far as Descartes' influence on the subsequent history of psychology is concerned, he was at least half of a disaster (see Esper, 1964, pp. 120-121). Whether one judges the mechanical or the phenomenological aspects of Descartes' psycho-physiology to be the disaster depends on one's philosophical bias.

Darwin was not responsible for the development of comparative psychology during the second half of the nineteenth century. As Jaynes points out, "Herrnstein and Boring (1965) are quite wrong in thinking that comparative psychology was a completely Darwinian affair; it was founded, at least in name, by anti-Darwinian sentiment in France" (Jaynes, 1966, p. 101). Millenson (p. 8) quotes Boring (1929) in support of the prevailing contrary opinion.
Thorndike did not perform the earliest experiments on "voluntary behavior" (p. 9). We need only mention F. C. Donders' (1862) work on reaction time, well described in Boring (1950) and Keller and Schoenfeld (1950), or Wilhelm Preyer's work with animals (1881), Möbius' once well-known demonstration of avoidance-training in the pike (see Washburn, 1908), and a host of others.

What disturbs us more than the many inaccuracies is the "Hegelian" finale of this first chapter. The indirect influence of popular misconceptions of Hegel's philosophy of history first shows up in Millenson's uncritical adoption of E. G. Boring's Zeitgeist. It is the last section, however, entitled "In Review" (p. 17) which briefly sums up Millenson's view of the march of progress in "the history of behavior science." Let us point out in passing that the popular views on Hegel are a myth, and that the common accusation (e.g., Popper, 1945) that Hegel conceived of the Prussian state of Frederick Wilhelm as the culmination of the march of God (Spirit) through the world is a fiction (see Kaufman, 1959, for further details). Even so, the label "Hegelian" is commonplace for such a view, and Millenson, unfortunately, distorts the history of psychology as much as Hegel, falsely or not, has been accused of doing. The march of progress in behavior theory has not culminated in the work of B. F. Skinner nor do his extensive contributions make it unnecessary to mention the labors of such contributors to the history of behaviorism as W. J. Crozier, J. R. Kantor, E. R. Guthrie, W. S. Hunter, E. C. Tolman, and Clark Hull, to mention only a few.

Chapters 2, 3, 4, and 5 move on to present the actual basic elementary material, both conceptual as well as factual, which is to prepare the reader for the treatment of later, more complex material, and follow the order of discussion found in the first four chapters of Keller and Schoenfeld. That is, no doubt, an excellent way to begin a systematic discussion of behavior in an introductory text or systematic treatise: one moves from the relatively simple and "basic" to the more complex, building one's structure from the ground up. But we do not think these chapters do the job well. With respect to their structure, the following comments may be made. The order of discussion of subjects within these four chapters is very similar to that used by Keller 
and Schoenfeld (1950). In general, however, Millenson's treatment is more sparse. In the chapter on Pavlov, for example, discussion of compound stimuli and higher-order conditioning are omitted. Following Keller and Schoenfeld, there is a sub-section entitled "The Extension of Classical Conditioning". Keller and Schoenfeld, however, deal mainly with (1) the Hudgins (1933) type of study as an illustration of the possibility of the development of voluntary control of respondent (autonomic) functions by way of Pavlovian conditioning, and, (2) the problem of pseudoconditioning. Millenson's comments, however, deal with a different topic entirely: the point is made that not all reflexes can be conditioned. This is followed by a further discussion of the inadequacy of the principle of "stimulus substitution", already discussed at length (pp. 42-43). The adequacy and clarity of this treatment may be judged by comparing it with the discussion of the same problem by Kimble (1961, pp. 52 ff.).

Part II is entitled "The Fundamental Units of Behavior". Its title implies a discussion of basic concepts in an analysis of behavior, but a discussion of "fundamental units", data, or concepts was given already in Chapters 2 through 5, where "stimulus", "response", "conditioning", and "operant", as well as "respondent", "extinction", etc., were all discussed.

One reason for the title of Part II may be found in the content of Chapter 6 ("Response and Stimulus Contingency Notation") and Chapter 8 ("Response Specification"). Chapter 6 could be considered an introduction to a notation system (see Mechner, 1959) as important to the analysis of behavior as Berzelius' shorthand notation system in chemistry. If, however, such was the rationale, Chapter 7 ("Intermittent Reinforcement") clearly does not belong, as will be discussed below.

Part II could have made excellent structural sense if it had consisted of three chapters, with the following suggested titles:

(a) The Specification of the Stimulus.

(b) The Specification of the Response.

(c) A Stimulus and Response Contingency Notation.

The "notation system" chapter could have come either before or after the other two chapters, but considering its intricacies and relative complexity, we feel that it would have been best placed after the other two chapters.

We note that the title of Chapter 6 ("Response and Stimulus Contingency Notation") and the order of Chapters 8 ("Response Specification") and 9 ("Environmental Control") contain a curious and unexplained reversal. Why is "response" discussed ahead of "stimulus"?

It also strikes us as illogical that the contents of Chapters 8 and 9 are not "symmetric". Chapter 8 begins with an extensive discussion of the notion of "response class", which leads to a restatement of the concept in terms of some elementary notions from set theory using Venn diagrams. This is followed by a more detailed discussion of data obtained employing several different response dimensions by way of the concept of "response differentiation": response force (without mention of Notterman and Mintz, 1965) and lever displacement (Herrick, 1963; 1964) are briefly discussed, but response duration (e.g., Margulies, 1961) and latency (e.g., Skinner, 1950; Stebbins and Lanson, 1961) are, for reasons unknown, omitted. Rate as a "differentially reinforceable" dimension of operant behavior (mainly by way of DRL schedules) is not discussed until after a section entitled "Extension of the Concept of the Operant". No similar or comparable treatment of the generic nature of the stimulus (see Skinner, 1935, 1938) is to be found in Chapter 9, which provides only a very brief and inadequate discussion of wavelength and intensity of light as "stimulus dimensions". All other sensory modalities are ignored. Directly relevant and basic questions about measurement and the problem of quantitative laws or functional relationships in the analysis of behavior are nowhere to be found (see Crozier, 1929; Hull, 1943; Skinner, 1938; Woodrow, 1942; Galanter, 1966; etc.).

Chapter 7, "Intermittent Reinforcement," does not belong here. Its more natural and logical place would have been in Part I, immediately after Chapter 5 ("Operant Extinction and Reconditioning"). That is, of course, where Keller and Schoenfeld discussed such "simple" schedules as Skinner's periodic conditioning and fixed-ratio reinforcement. In 1950 it was still possible to discuss such matters in one common chapter with material on simple acquisition and extention. Today a separate chapter is necessary, but the location 
in the middle of Part II, "The Fundamental Units of Behavior," makes no sense to us. This is a curiously short chapter, for it is in this area beyond all others that operant conditioning has made a unique contribution. Unlike the topics of discrimination and stimulus control, which have a rich history in the study of sensation-perception, psychophysics, and early mazelearning studies, or motivation with an equally extensive past, the study of schedules of reinforcement is almost entirely the product and creation of "the experimental analysis of behavior". Any precursors to the study of schedules are anecdotal, metaphorical, or, at best, unsystematic and somewhat trivial. It is here, also, that one can find extensive, active and sophisticated activities in terms of both empirical-theoretical progress and successful technological application. If this, however, is operant conditioning's success story, it does not come across in this chapter.

In part, the brevity of the chapter is achieved by consigning ratio schedules to a different chapter on "Response Specification". If the intent of the chapter is to provide an account of the "classical" schedules, this leaves us with the somewhat sparse presentation of FI and VI schedules-which is just what is provided in section 7.1. It is brief, omits early basic data, such as Wilson (1954), and does not provide a sufficiently precise description of either schedule to prepare the student to construct an example of these schedules on his own. If "classical" schedules are being presented, we wonder if the DRL schedule has not earned the right to mention? If the aim is to break away from the restrictive traditional classification of schedules into FI, VI, FR, and $V R$, and indicate instead the existence of infinite possibilities of stating rules relating the response-reinforcement contingency, sections 7.2 and 7.3 do not come close to suggesting DRO schedules, DRH schedules, limited-hold contingencies, differential reinforcement of interresponse times, etc., nor even hint at the possibilities of subtle behavioral control that led Reynolds (1968, p. 60) to write: "Schedules are the mainsprings of behavioral control, and thus the study of schedules is central to the study of behavior."

The possibility of using the topic of reinforcement schedules to integrate data from several areas to make contact with the discrimination literature via multiple schedules or conditioned reinforcement via chained schedules was not exploited. The decision to include FR schedules within the discussion of differentiation and shaping did not take advantage of the possibility for integration either. Instead we find the comment ". . . the FR specification provides an alternative method to a schedule to produce perseverance" (p. 173; italics ours). Is this not moving in the wrong direction, to fractionate the schedule material rather than to integrate in the way suggested?

Further, if the goal is to present a current sampling of schedules research, there is no mention of tandem schedules, mixed schedules, conjunctive schedules, concurrent schedules, etc. The research on compound schedules is "where it's happening" and the exclusion of these data is a failure to present the progress made in dealing with complex situations and a lost opportunity to portray the excitement of recent research developments. Nor is there any indication of the extensive behavioral engineering applications of schedule research, other than the presentation of Holland's (1958) studies of observing behavior.

Part III, entitled "Compounding Behavioral Units," evokes associations in terms of some new "behavioral chemistry" and, presumably, refers back to the comparison of the Mechner notation system with the, at present, more prestigious one used in chemistry. If, however, one expected to see a further development of the system, either in its own right or as applied to more complex experimental paradigms than simple schedules of reinforcement or simple discrimination studies in which the animal is presented with simple stimuli, one would be very much disappointed. Instead, there are three chapters dealing with "Discrimination", "Acquired Reinforcers", and "Chaining" respectively. The use of the notation system, so elaborately discussed in Chapter 6, in minimal. In Chapter 10 ("Discrimination"), its complexity does not go beyond that presented in Chapter 6, which briefly discussed the use of the notation system in describing "discriminations" (compare p. 135 with pp. 217, 220, 223, and 230), even though this subject had not at all been discussed previously. Chapters 11 and 12 do extend the use of the notation system to simple sequences of operants (chains). In Chapter 12 "simple repetitive chains" are depicted as 
"loops", but this way of diagramming is dropped again later in the chapter, which reverts back to an earlier scheme used to depict "repetitive contingencies" in Chapter 6 (p. 131). The reason for these switches from one type of diagramming to another is not explained, nor is a connection between "loops" and "repetitive contingencies" made explicit. As we stated before, the emphasis of these chapters is not on the Mechner notation system; they serve mainly to present some elementary material relevant to their titles.

Since Part III does not live up to the abovediscussed implication of its title, one might conclude that it must refer to the second possible meaning: it simply deals with more complex material than Part II. That is debatable, but, if that is the case, the title of Part IV becomes more puzzling still. Its Chapter 13, "Concept Acquisition" and Chapter 14, "Problem Solving and Intelligence", are, if anything, a continuation of the topics discussed in Chapter 10 (discrimination) and Chapter 12 (chaining). Why such matters here become "complex contingencies", rather than the further "Compounding (of) Behavioral Units" is not clear.

The logic behind the choice of the title for Part V, "Reinforcement Dynamics", is equally obscure. Its chapters deal with that traditional stronghold of psychological phlogiston theory; "incentive", "motivation", "drive" (appetite), and "aversion" are all discussed in the traditional confused and confusing fashion. If this be "Reinforcement Dynamics", one wonders what many of the preceding chapters were all about. The content of the last chapter ("Emotional Behavior") does not seem to fit in with any possible interpretation of the meaning of "Reinforcement Dynamics". If it does, it is nowhere explained how. It appears to be merely a final and gratuitous miscellany filled with an ancient and venerable anachronisms that often spoil the more popular and non-systematic introductory texts.

The basic test of a textbook, however, is "does it teach"? Eventually the student audience will give us the answer. In the meantime, a few guesses can be made. Since operant conditioning has given rise to programmed instruction, we might well expect to find here the application of some programming principles. Short of producing a programmed text, the possibilities are many, as Ferster and Per- rott's recent book, Behavior Principles (1968), has shown.

One gesture toward effective teaching might have been the serious development of exercises providing the occasion for the student to respond and test his newly acquired repertoire. Since there are only 12 exercises (and three of these in the last chapter) and no answer key, their inclusion seems to have been an afterthought. They do not represent a skillful application of the notions of successive approximation to some desired terminal behavior.

Another helpful prompt might have been a glossary of technical terms. Instead, we find terms used without any definition (for example, "penumbra regiov" on p. 21) or definitions which, if not wrong, are, at least, misleading (e.g., "set" as "the repeated emission of inappropriate behavior in a problem situation" on p. 336). Can we expect the student to appreciate such unamplified comments as: "The stimulus is the arbitrary environmental unit" (p. 188); "Figure 9-6 indicated various sound intensities in terms of a logarithmic scale called decibels" (p. 192); or to understand why Section 8.9 on "The Language and Logic of Sets" is appended without transition or explanation at the end of Chapter 8 on "Respose Specification"?

The addenda to Chapters 2, 5, 7, 8, 10, and 14 on statistics, set theory, and behavioral steady states, in each case, contain more information than the knowledgeable reader needs for review purposes but less than the naive reader would require to comprehend these rather complex matters. We cannot conceive of an audience for whom these particular sections would be appropriate.

There is also the "four-part structural representation" of various paradigms into "given", "procedure", "process", and "result". The poverty of this classification is best seen in that in its application on p. 78 "process" and "result" turn out to be the same, and on p. 294, there is no "given". Here we have the superficial trappings of analysis, but without substance.

There are points of unbelievably abrupt transitions from one topic to another (pp. 272, $277,326,345)$; transitions where it is difficult to detect where a quotation ends (p. 106); instances of unnecessary jargon ("heuristics", p. 341); lost opportunities to expand on the prac- 
tical applications of research (p. 146); somewhat rambling sections (pp. 310-318); and failures to relate material to relevant earlier sections (p. 154).

Perhaps more serious than anything mentioned above is the failure of the book to suggest the great gaps in our knowledge or impart a feeling for the unsolved problems. There is no excitement here to entice the young student to go on, hardly a hint of the research that needs to be done, or recognition of how far short we are of an even adequate theory of behavior. As an example, we mention what may well be the most uncritical and dogmatic discussion of conditioned reinforcement in the literature. It is not just that the author ignores that the so-called "Keller and Schoenfeld hypothesis" (see Wike, 1966, pp. 25-26) has found little favor and experimental support (Kelleher and Gollub, 1962), it is the complete absence of an indication that there are any question or problems left to be answered that is most disturbing. Perhaps, there are those who will be content to learn that "The problem of how to study acquired motives was solved in Chapter 11 ["Acquired Reinforcers"] by formulating a set of principles for converting any arbitrary stimulus situation into a conditioned reinforcer" (pp 365).

Can such a presentation produce students prepared and motivated to advance the science of psychology? Our judgment is no.

\section{BIBLIOGRAPHY}

Aristotle. De motu animalium. In W. D. Ross (Ed.)., The works of Aristotle, Vol. 5. 11 Vols.; New York: Oxford University Press, 1908-1931.

Bernstein, B. J. (Ed.). Towards a new past: dissenting essays in American history. New York: Pantheon, 1967.

Boring, E. G. A history of experimental psychology (1929). 2nd ed.; New York: Appleton-Century-Crofts, 1950.

Brett, G. S. A history of psychology. 3 Vols.; London: Allen and Unwin, 1912-1921 (New York: Macmillan).

Clagett, M. The science of mechanics in the middle Ages. London: Madison, 1959.

Cofer, C. H. and Appley, M. H. Motivation: theory and research. New York: Wiley, 1964.

Crombie, A. C. Medieval and early modern science. 2 Vols.; Garden City, N.Y.: Doubleday, 1959.

Crozier, W. J. The study of living organisms. In C. Murchison (Ed.), The foundations of experimental psychology. Worcester, Mass.: Clark University Press, 1929. Chapter 2. Pp. 45-127.
Denake, T. G. A concise history of codpieces. Amsterdam: Kloot and Vel, 1966.

Esper, E. A. A history of psychology. Philadelphia: Saunders, 1964.

Ferster, C. B. and Perrott, M. C. Behavior principles. New York: Appleton-Century-Crofts, 1968.

Galanter, E. Textbook of elementary psychology. San Franscisco: Holden-Day, 1966.

Herrick, R. M. Lever displacement during continuous reinforcement and during a discrimination. Journal of Comparative and Physiological Psychology, 1963, 56, 700-707.

Herrick, R. M. The successive differentiation of a lever displacement response. Journal of the Experimental Analysis of Behavior, 1964, 7, 211-215.

Herrnstein, R. J. and Boring, E. G. A source book in the history of psychology. Cambridge, Mass.: Harvard University Press, 1965.

Holland, J. G. Human Vigilance. Science, 1958, 128, 61-67.

Holland, J. G. and Skinner, B. F. The analysis of behavior: A program for self-instruction. New York: McGraw-Hill, 1961.

Hudgins, C. V. Conditioning and the voluntary control of the pupillary light reflex. Journal of General Psychology, 1933, 8, 3-51.

Hull, C. L. Hypnosis and suggestibility: an experimental approach. New York: Appleton-CenturyCrofts, 1933.

Hull, C. L. Principles of behavior: an introduction to behavior theory. New York: Appleton-CenturyCrofts, 1943.

Jaynes, J. The routes of science. American Scientist, 1966, 54, 94-102.

Kantor, J. R. Principles of psychology. 2 Vols.; Bloomington, Ind.: Principia Press, 1924/1926.

Kantor, J. R. The scientific evolution of psychology, Vol. 1. Chicago: Principia Press, 1963.

Kaufman, W. From Shakespeare to existentialism (1959). Garden City, N.Y.: Doubleday, 1960.

Kelleher, R. T. and Gollub, L. R. A review of positive conditioned reinforcement. Journal of the Experimental Analysis of Behavior, 1962, 5, 543-597.

Keller, F. S. and Schoenfeld, W. N. Principles of psychology: a systematic text in the science of behavior. New York: Appleton-Century-Crofts, 1950.

Kimble, G. A. Hilgard and Marquis' conditioning and learning. New York: Appleton-Century-Crofts, 1961.

Margulies, S. Response duration in operant level, regular reinforcement, and extinction. Journal of the Experimental Analysis of Behavior, 1961, 4, 317-321.

McKeon, R. The basic works of Aristotle. New York: Random House, 1941.

Mechner, F. A notation system for the description of behavioral procedures. Journal of the Experimental Analysis of Behavior, 1959, 2, 133-150.

Miller, G. A. Psychology: the science of mental life. New York: Harper \& Row, 1962.

Munn, N. L. Handbook of psychological research on the rat. Boston: Houghton Mifflin, 1950.

Notterman, J. M. and Mintz, D. E. Dynamics of response. New York: Wiley, 1965.

Parmelee, M. The science of human behavior. New York: Macmillan, 1913.

Popper, K. R. The open society and its enemies. London: Routledge \& Kegan Paul, 1945. 
Preyer, W. T. Die Seele des Kindes (The Mind of the Child). Leipzig: Fernau, 1881.

Randall, J. H., Jr. Aristotle. New York: Columbia University Press, 1960.

Reynolds, G. S. A primer of operant conditioning. Glenview, Ill.: Scott, Foresman, 1968.

Shute, C. The psychology of Aristotle: an analysis of the living being. New York: Columbia University Press, 1941.

Skinner, B. F. The concept of the reflex in the description of behavior. Journal of General Psychology, 1931, 5, 427-458.

Skinner, B. F. The generic nature of the concepts of stimulus and response. Journal of General Psychology, 1935, 12, 40-65.

Skinner, B. F. The behavior of organisms: an experimental analysis. New York: Appleton-CenturyCrofts, 1938.

Skinner, B. F. Are theories of learning necessary? Psychological Review, 1950, 57, 193-216.

Skinner, B. F. Science and human behavior. New York: Macmillan, 1953.

Sokolov, R. A. Attacking sacred cows. Newsweek, April 22, 1968, pp. 99-102.

Stebbins, W. C. and Lanson, R. H. A technique for measuring the latency of a discriminative operant.
Journal of the Experimental Analysis of Behavior, 1961, 4, 149-155.

Taylor, L. W. Physics: the pioneer science. Boston: Houghton Mifflin, 1941.

Toulmin, S. and Goodfield, J. The architecture of matter. New York: Harper \& Row, 1962.

Verhave, T. Joseph Buchanan (1785-1829) and the 'Law of Exercise' (1812). Psychological Reports, 1967, 20, 127-133.

Washburn, M. F. The animal mind: a textbook of comparative psychology. New York: Macmillan, 1908.

Watson, R. I. The great psychologists from Aristotle to Freud. Philadelphia: Lippincott, 1963.

Whitehead, A. N. The aims of education. New York: Macmillan, 1929.

Wike, E. L. Secondary reinforcement: selected experiments. New York: Harper \& Row, 1966.

Wilson, M. P. Periodic reinforcement interval and number of periodic reinforcements as parameters of response strength. Journal of Comparative and Physiological Psychology, 1954, 47, 51-56.

Woodrow, $H$. The problem of general quantitative laws in psychology. Psychological Bulletin, 1942, 39, 1-27. 